\title{
Study on influence factors of repeated purchase behavior of e-commerce consumers
}

\author{
Yan Qu \\ Shandong Yingcai University, Ji'nan, 250104, China
}

\begin{abstract}
Keywords: e-commerce; repeated purchase; influence factor
\end{abstract}
\begin{abstract}
: e-commerce based on internet and information technology has become an important force of modern commerce. Due to virtual network marketing and many uncertain factors, repeated purchase rate of e-commerce consumers is much lower than traditional commercial purchase rate. So, it is vital to break through consumers' repeated purchase obstacles for expanding e-commerce transaction volume. Under the background of e-commerce environment, this paper analyzes and studies various factors influencing consumers repeated purchase behavior in four parts. It is believed that transaction reliability, information safety, reputation guarantee and price advantage are key factors influencing repeated purchase behavior of e-commerce consumers. Besides, his paper proposes measures to standardize e-commerce management.
\end{abstract}

With rapid development of network technique in China and continuous rise in the number of netizens, e-commerce based on internet and information technology has become a force of modern commerce. $^{[1]}$ As e-commerce influence and coverage expand continuously, enterprises select e-commerce mode one after another in order to increase modern market competitiveness and actively launch all kinds of network marketing modes. Consumers' repeated purchase intention refers to the will or tendency of consumers to make deals with the merchant again after one transaction with the network merchant. ${ }^{[2]}$ In the face of the complex and ever-changing e-commerce market full of uncertainties, repeated purchase behavior is vital for marketing management, for keeping old customers can usually gain greater income than gaining new customers. So, it is very necessary to study the factors influencing consumers' repeated purchase behavior under e-commerce environment and how to improve repeated purchase rate of e-commerce consumers and retain existing consumers.

\section{Connotation and superiority of e-commerce}

\subsection{Connotation of e-commerce}

E-commerce is a new trading mode which is based on modern information technology and network technique, integrates financial service computerization, management informatization and business information networking and aims to achieve harmony and unity of logistics, capital flow and information flow. E-commerce breaks through production and circulation mode of traditional commerce and trade, surpasses space-time concept, omits the disadvantage of hierarchical operation channel, greatly reduces the distance between allocation and consumption, makes logistics, capital flow and information flow transmit faster, makes circulation channels wider, opens up a fair, just, wide and competitive virtual network market and provides the platform for manufacturers, sellers and consumers to satisfy their own needs.

1.2 Superiority of e-commerce

Compared with traditional trade, e-commerce has the following advantages:

1.2.1 Virtual market

E-commerce is a transaction mode based on internet. Both parties participating in transactions complete transactions via network, from confirming purchase intention, product display, price negotiation, confirming transactions and paying. Both parties can finish the whole transaction process without meeting. Such e-commerce transaction process is completely virtual. Enterprises only exist in network and form a special transaction form with small tangible boundary and large 
intangible boundary.

1.2.2 Transaction quickness

Since e-commerce is based on network system, the computer is very convenient and fast in data processing, e-payment, bank transfer, insurance, consignment of goods and declaration, without personnel intervention. Thus, transaction speed increases greatly. The whole transaction process is simple and fast.

\subsubsection{Low cost}

E-commerce makes transaction cost of both buyers and sellers greatly reduce. Since both parties trade via network, information cost of both parties declines. Buyers can save traffic and capital cost as well as time cost. No intermediary involves in e-commerce which reduces relevant transaction links and expenses. Sellers do not need to advertise, distribute brochures and pay TV advertising fee. So, activity cost of both parties greatly decreases.

\subsubsection{Operation simplicity}

Compared with traditional enterprises, e-commerce needs no store, storage facilities and product display site. So, relevant rent reduces. In addition, product publicity and sales do not need houses and other facilities. All can be carried out on network. As internet popularizes and commercial development, e-commerce will gradually develop toward family work in the future. This greatly reduces e-commerce capital and makes operation simple.

\subsubsection{Sufficient trading time}

Internet achieves 24h service. Anyone around the world can carry out commercial activities anywhere and anytime. Without the limitation of on and off duty, taking stock and time difference, business can be conducted anytime. Besides, anyone can counsel information and inquire business anytime and anywhere, without national boundary. Network business can expand to the market range traditional sales and advertising promotion cannot reach. This increases infinite business opportunities for enterprises.

\section{Effects on consumers' purchase decision}

Before consumers confirm their purchase behavior, they will collect and compare product information. Philip Kotler - a marketing management expert classifies consumers' purchase decision-making process into five aspects: need, gathering information, evaluation selection, deicing to purchase and the process after purchase [3]. Influence factors of e-commerce on consumers' purchase behavior mainly include the following:

2.1 Effect on need recognition

Traditional commerce generally adopts TV, network and media to expand product influence and coverage and stimulate consumers' purchase psychology. E-commerce takes different forms of external stimulus to influence consumers' need cognition and stimulate their purchase psychology and desire. As network coverage and the number of netizens are on the rise, the influence mode of e-commerce on consumers' need cognition will continuously improve.

\subsection{Effect on information gathering}

Before consumers purchase a product, they will gather and analyze product information through internal and external channels. Internet-based e-commerce can provide more convenience for consumers to collect product information. Thus, it greatly improves information gathering efficiency and reduces information gathering cost. Consumers collect, analyze, track and inquire information via network and generate new purchase impulsion through browsing new information. Such keen sense of purchasing guides network consumption tide.

\subsection{Effect on purchase cost}

Under traditional commercial conditions, before consumers purchase a product, they need to gather product information in stores, then compare products and finally decide purchase and payment. Under e-business environment, consumers can save selection and comparison time. As long as they complete e-payment, the goods will be delivered to consumers safely. Consumers do not need to search, compare and analyze products in multiple stores, let alone bargain with merchants. Thus, consumers' purchase cost decreases enormously. 


\subsection{Effect on purchase decision}

Compared with traditional commerce consumers, e-commerce consumers have three differences in purchase decision. Firstly, e-commerce consumers carefully gather, analyze and compare information before the purchase, so rational factor is more than emotional factor. Secondly, in online shopping, consumers rarely follow others' opinions and are not influenced by external factors. Thirdly, after the consumer chooses the product, they generally place an order and purchase it. Thus, time cost is saved. However, since e-commerce just starts, e-commerce management is imperfect and it is necessary to combine online shopping and traditional commercial activities tp finally complete transactions.

2.5 Effect on post-purchase behavior

After consumers purchase products, they will analyze and evaluate product quality, property and after-sale service so as to test whether the product is correct. Such evaluation and analysis process is a significant link to decide whether consumers repeat to purchase the product. If product quality makes consumers satisfied or surpasses consumers' expectation, consumer satisfaction will boost and meanwhile their repeated purchase rate will increase. On the contrary, if consumers are dissatisfied with the product, they will list the product in the blacklist. Manufacturers thus lose these potential repeated purchasers.

\section{Factors influencing consumers' repeated purchase}

Repeated purchase behavior is vital for marketing management. This has been proven by many literatures. This is because keeping old customers can usually gain greater income than gaining new customers. [4] Lee and Uchenna adopt extensible technology acceptance model to analyze B2C website and draw such conclusion that website reputation, trust and reliability can significantly influence consumers' repeated purchase intention [5]. It thus can be known that transaction reliability, information safety, reputation guarantee and price advantage are key factors influencing consumers' repeated purchase behavior.

\subsection{Transaction reliability}

Consumers pay much attention to online shopping safety and have doubts, so shopping safety is the question consumers will consider first. This is also a significant factor influencing consumers' final purchase decision. As media and network often report e-bank account stealing and transaction fraud, or some repeated purchasers may experience unsafe shopping behaviors, consumers doubt or distrust online shopping safety. Firstly, they worry the transaction is a fraud; secondly, they cannot judge product quality; thirdly, the product has differences with pictures; fourthly, they worry whether the delivery is timely; fifthly, after-sale service has no guarantee or after-sale service efficiency is low. These factors greatly influence consumers' repeated purchase behavior.

\subsection{Information safety}

E-commerce is based on internet and other information technologies. Similar to traditional transaction activities, e-commerce includes commercial flow, currency flow, logistics and information flow. Since e-commerce transaction is conducted under virtual environment, consumers and merchants cannot carry out effective face-to-face communication and see the products to be purchased. Transactions in virtual environment cause that information flow is not synchronous with commodity logistics, capital flow and commodity value flow in time and space. Thus, transaction loss risk can easily occur. These factors impost effects on consumers' repeated purchase behavior.

\subsection{Reputation guarantee}

Online shopping reputation contains merchants' service attitude, evaluation results of other consumers and after-sale service quality. Since consumers, merchants and products are separated in e-commerce, communications between both parties, consumers' evaluation on commodity and evaluation of other consumers on merchants are of great importance. Therefore, the merchants with high reputation will generate positive effects in consumers' repeated purchase.

3.4 price advantage

Under e-commerce background, both parties cannot communicate face to face, let alone see product quality. However, since network merchants do not need to pay store rent and other expenses, 
the transaction cost is low. Thus, commodity price has a great advantage compared with stores. If consumers cognize the commodity price offered by online merchants is lower, consumers' purchase will is stronger [6]. So, price advantage is an important factor attracting consumers' repeated purchase.

\section{Measures to standardize e-commerce management}

\subsection{To enhance information safety publicity}

Consumers' worry about information safety will have direct impacts on their repeated purchases behavior. So, it is required to enhance e-commerce information safety publicity, reduce or stop behaviors damaging online shopping safety and enhance consumers' safety mentality.

4.2 To strengthen safety authentication

E-commerce is a virtual trade. Its exit cost is lower than that of traditional transaction mode. Consumers are in the weak position. In transaction disputes, the difficulty in gaining evidence increases. This to some extent influences consumers' repeated purchase behavior. To enhance the third party certification of e-commerce and guarantee information and transaction safety can effectively reduce consumers' worry about transaction safety and increase repeated purchase will.

4.3 To perfect supporting services

In e-commerce, the products, services and after-sale services provided by merchants have some defects and shortcomings. When merchants carry out product publicity, they should improve in ordering goods, paying and distribution items, further simplify and optimize selection and purchase approaches and provide high-quality supporting services for consumers.

\section{Conclusions}

As internet economy develops rapidly, network economic development arising from e-commerce mode develops also rapidly. The survey reports from Data Center of The China Internet show in the first half year of 2010, total network consumption reached 473.4 billion; it is predicted the proportion of online shopping consumption to total online consumption in 2011 would break through $50 \%$, reaching about $55.8 \%$ [7]. E-commerce is increasingly accepted and cognized by vast consumers while bringing great prosperity to social economy. Besides, it attracts traditional enterprises and various kinds of internet enterprises. Whole network sales trend forms gradually. Therefore, winning the fixed consumer groups is an important weight for merchants to win this commercial war. According to Pareto Law, 20\% loyal customers bring $80 \%$ profits for an enterprise [8]. Repeated purchase of e-commerce consumers is influenced by multiple factors, mainly including transaction reliability, information safety, reputation guarantee and price advantage. Thus, it is required to enhance e-commerce management, provide safe and reliable e-commerce with quality and reputation guarantee for consumers and make shopping environment further accord with consumers' repeated purchase psychology so as to attract consumers, ensure their rights and interests, and promote rapid and benign development of e-commerce.

This paper is a part of 1. The topic of 2013 Shandong Yingcai College (topic No.: 13YCYBRW02) and 2. The topic of 2012 Shandong Yingcai College (topic No.: 12YCYBRW12).

\section{References}

[1] Li Juan, Zeng Xiaochun, Study on consumers' purchase decision-making process under e-business environment. Economic development and management innovation -collected papers from the $10^{\text {th }}$ academic annual conference of industrial technology research institute for nationwide economic management colleges, 2010: 222-225

[2] Philip Kotler, Marketing management (14 ${ }^{\text {th }}$ Version, global version). China Renmin University 
Press, 2012, 4

[3] Dong Xuelei, Study on factors influencing consumers' repeated purchase behavior. Dalian University of Technology, 2007 (2): 1-69

[4] Dong Yali, Yang Bei, Analysis of factors influencing consumers’ purchase behavior under C2C e-commerce platform. Consumption Economy, 2007, 23 (3): 34-37+40

[5] Chen Yiwen, Ma Jiwei, consumers' purchase decision-making and its influence factors in e-commerce. Advances in Psychological Science, 2012 (1): 31-38.

[6] Cai Jie, Study on factors influencing consumers' repeated purchase intention under network environment. Northeastern University, 2009 (6): 1-73. 